\title{
Avaliação do impacto ambiental causado pelas alterações espaço temporal do uso do solo e da cobertura vegetal utilizando o modelo das cadeias de Markov
}

\author{
Environmental impact assessment caused by the timeline changes from the land use and \\ vegetation cover using the model of Markov chains
}

\author{
Jomil Costa Abreu Sales ${ }^{1}$, Darllan Collins da Cunha e Silva², Ligia Ferrari Torella di Romagnano ${ }^{3}$, \\ Rana Bertagna $a^{4}$ Roberto Wagner Lourenço $0^{5}$ \\ 1,2,4,5 Universidade Estadual Paulista "Júlio de Mesquita Filho" \\ jomilc@gmail.com; darllanamb@yahoo.com.br; r_bertagna@hotmail.com; robertow@sorocaba.unesp.br \\ ${ }^{3}$ Instituto de Pesquisas Tecnológicas - IPT \\ lferrari@ipt.br
}

\begin{abstract}
Resumo
As técnicas de geoprocessamento têm sido cada vez mais recorrentes no entendimento dos efeitos causados por atividades antrópicas sobre o meio ambiente. Assim, esse estudo teve como objetivo a aplicação de uma metodologia visando à construção de um modelo de predição probabilística que possa demonstrar por meio de cenários futuros as alterações no uso do solo e cobertura vegetal, empregando o modelo das Cadeias de Markov, possibilitando analisar o impacto causado pelo nível de transição espacial e temporal entre o uso do solo e atividades canavieiras em Unidades de Conservação e suas zonas de amortecimento. Para isso, foi utilizado o modelo de Markov visando a construção de um cenário de predição probabilística futura para 20 anos em função do avanço da atividade canavieira na região. Desta forma, foi possível verificar que as classes de pastagens e agriculturas, com destaque para a atividade canavieira, atuam de maneira incisiva na contribuição das alterações e avanços sobre as classes de matas e matas ciliares com probabilidades acima de 30\% de suas áreas serem substituídas por essas atividades antrópicas, tanto na Zona de Amortecimento, como no interior da UC.
\end{abstract}

Palavras-chave: Modelo de Markov. Cobertura vegetal. Cana-de-açúcar. Geoprocessamento.

\begin{abstract}
The geoprocessing techniques have been increasingly recurrent in understanding the effects caused by human activities on the environment. This study aimed to apply a mapping methodology to building a probabilistic prediction model, that could be able to demonstrate through the future scenarios, changes in land use and vegetation cover, using the model of Markov Chains, enabling the analysis of the impact caused by the spatialtemporal transition level and between the land uses and the sugar cane plantation in protected areas and their buffer zones. For this, was used the Markov model for the construction of a future probabilistic prediction, to a 20 years scenario, due to the advancement of sugarcane activity in the region. Thus, we found that pastures and agriculture, especially the sugar cane activity, act incisively on the contribution of changes and advances on classes of forests and riparian forests, with probabilities over than $30 \%$ of their areas being replaced by these human activities in both the Buffer Zone, as well inside the reserve.
\end{abstract}

Keywords: Markov model. Vegetation cover. Sugar cane. Geoprocessing. 


\section{Introdução}

A pressão antrópica sobre o ambiente natural contribui significativamente com a redução da diversidade biológica, sendo que a produção agrícola e o crescimento populacional estão entre os principais fatores desencadeadores de problemas na área ambiental. Prova disso, pode ser atribuída à taxa com que o homem está alterando as paisagens naturais, a qual é muito maior que a dinâmica de perturbação natural dos ecossistemas (OKA-FIORI et al., 2003; RIBEIRO, 2011; ARIMA et al., 2014).

Do ponto de vista agrícola, destaca-se a cultura de cana-de-açúcar, que tem um papel importante na economia das últimas décadas, estimulada pela busca de alternativas renováveis de energia e produção de biocombustíveis em substituição aos combustíveis fósseis, mais nocivos ao meio ambiente (ABDALA; CASTRO, 2010; CHEAVEGATTI-GIANOTTO et al., 2011). O Brasil é o maior produtor de cana-de-açúcar do mundo, sendo o Estado de São Paulo responsável por cerca de $60 \%$ do total de etanol produzido no país, além de reconhecida posição de destaque em diversas pesquisas relacionadas com a área (NEVES; CONEJERO, 2007; GOLDEMBERG et al., 2008).

No entanto, a expansão do cultivo de cana-de-açúcar para atender a crescente demanda mundial, também pode ser analisada de forma preocupante do ponto de vista ambiental (GONÇALVES, 2009; MARTINELLI et al., 2010). Por exemplo, a safra 2012/2013 da região sudeste avançou de 246.011 hectares para 357.183 hectares plantados (CONAB, 2012).

Isso se deve ao fato que boa parte da expansão territorial do cultivo invariavelmente ocorre sobre outros tipos de uso do solo, sendo uma das mais prejudicadas as relacionadas à cobertura vegetal, em especifico, as matas que protegem os morros e as vertentes, bem como as que protegem os cursos d'água.

Desta forma, Pereira et al. (2011) e Pereira et al. (2012) preveem a necessidade de zoneamentos ecológicos abordados com maior profundidade nos Planos de Manejo das principais Unidades de Conservação (UC's), além da inclusão de medidas gestoras nos Planos Diretores dos municípios, a fim de conter a expansão da atividade canavieira. Portanto, o estabelecimento das UC's é fundamental na tomada de decisões para delimitar os tipos de uso do solo na UC e em seu entorno quanto à conservação dos recursos naturais e sua utilização de maneira sustentável (RODRIGUES, 2005).

Neste sentido, estudos da alteração temporal do uso do solo e da cobertura vegetal são imprescindíveis para o planejamento e organização territorial, a fim de garantir o uso sustentável dos recursos naturais existentes e preservá-los para gerações futuras (RIBEIRO, 2011; PEIXE; TORRES, 2011, MENEZES, 2014). Por isso, o estudo da evolução espaço temporal das paisagens constitui o primeiro e mais importante passo para o entendimento da relação entre o homem e o meio físico, possibilitando, estimar consequências futuras, considerando a progressão de acontecimentos iniciados no passado (OKA-FIORI et al., 2003; VARAJÃO et al., 2009).

Portanto, o geoprocessamento pode auxiliar nos estudos da dinâmica da paisagem e expansão antrópica, através da interpretação de imagens de satélite, mapeamento do uso do solo e cobertura vegetal, a qual deve contribuir com a avaliação das alterações em unidades de conservação e seu entorno, possibilitando o desenvolvimento de práticas ambientais e políticas públicas voltadas para a manutenção e recuperação da biodiversidade, auxiliando na gestão de paisagens para a conservação biológica e uso sustentável dos recursos naturais (LINDENMAYER, 2008; SOMMER; SALDANHA, 2012).

Assim, vários modelos de simulação de mudanças do uso do solo vêm sendo empregados atualmente para avaliar e propor cenários futuros. Para os casos de cenários estacionários, o modelo das Cadeias de Markov tem sido utilizado com maior frequência.

Esta técnica é baseada em um modelo matemático que procura descrever como determinados processos se modificam ao longo do tempo por meio de uma sequência numérica de dados (ALMEIDA; GLERIANI, 2007).

Segundo Keller Filho et al (2006) as Cadeias de Markov são sistemas de transições de estados, onde os estados são representados em termos de seus vetores probabilísticos, que podem variar no espaço temporal (discreto ou contínuo), e as transições entre estados são probabilísticas e dependem apenas do estado corrente.

Vários estudos utilizaram o modelo de Markov para propor cenários futuros e avaliar as mudanças de uso do solo no tempo, como os de Muller e Middleton (1994) que quantificaram a urbanização das terras agrícolas na região do Niagara no Canadá no período de 1935 a 1981, de Sang et al (2011) que utilizaram o modelo de Markov para quantificar a urbanização e distribuição espacial do poluente chumbo no distrito de Fangshan em Pequim na China e de Wang et al (2012) que estudou o modelo de Markov para previsão de mudanças de uso da terra no distrito de Changping em Pequim para verificar a influência da resolução de imagens de satélites na simulação.

Desta forma, esse estudo apresenta a aplicação de uma metodologia visando à construção de um modelo de predição probabilística que possa demonstrar por meio de cenários futuros as alterações no uso do solo e cobertura vegetal empregando o modelo das Cadeias de Markov e possibilite analisar o impacto causado pelo nível de transição espacial e temporal entre o uso do solo e culturas de cana-de-açúcar em Unidades de Conservação e suas zonas de amortecimento. 


\section{Materiais e Métodos}

\section{1 Área de estudo}

A Unidade Conservação (UC) estudada é denominada de Floresta Nacional de Ipanema (Flona de Ipanema), a qual possui 5.069,73ha e está localizada no interior do Estado de São Paulo, abrangendo os municípios de Iperó, Capela do Alto e Araçoiaba da Serra. Trata-se de uma Unidade de Conservação (UC) de uso sustentável de acordo com o Sistema Nacional de Unidades de Conservação (SNUC).

Possui em seu entorno uma Zona de Amortecimento com raio de $10 \mathrm{~km}$ de distância a partir de seus limites (Figura 1). São abrangidos pela Zona de Amortecimento os municípios de Boituva, Iperó, Capela do Alto, Araçoiaba da Serra, Salto de Pirapora, Votorantim, Sorocaba, Tatuí, Sarapuí, Alambari e Porto Feliz, englobando uma área total de 73.851ha (MMA, 2005).

A Flona de Ipanema é uma das poucas áreas, do interior paulista, de expressiva cobertura florestal, e mesmo com notáveis perturbações ao longo de sua história, conta hoje com a maior biodiversidade da região. A área da floresta é composta por ambientes fragmentados, que podem variar de acordo com o tipo de solo, altitudes, regiões aluviais, afloramentos rochosos e intervenções humanas (SOUZA; MARTOS, 2008).

\subsection{Materiais}

Foram utilizadas imagens de satélite do sensor orbital TM/Landsat-5 de órbita e ponto 220/76, com 30m de resolução espacial, referentes aos meses de julho a setembro para análise histórica de nove anos consecutivos no período de 2003 a 2011 nos comprimentos de onda do visível, infravermelho médio e infravermelho distante. Essas imagens foram obtidas do Instituto Nacional de Pesquisas Espaciais (INPE). Foram obtidos também, do mesmo período, arquivos vetoriais das áreas de plantio de cana-de-açúcar, através do projeto CANASAT (CANASAT, 2014), além da base de dados contendo os limites territoriais, sistemas viários e a zona de amortecimento da Flona de Ipanema, adquiridas no Instituto Brasileiro de Geografia e Estatística (IBGE, 2006), enquanto que os dados de hidrografia foram extraídos do mapeamento realizado pela Agência Nacional de Águas (ANA, 2014).

Foi utilizando o software Idrisi Selva para processamento e tratamento das imagens de satélite e elaboração da base de dados e integração das demais informações espaciais.

\subsection{Métodos}

Foi realizada a correção de posicionamento (georreferenciamento) das imagens de satélite através do ajuste

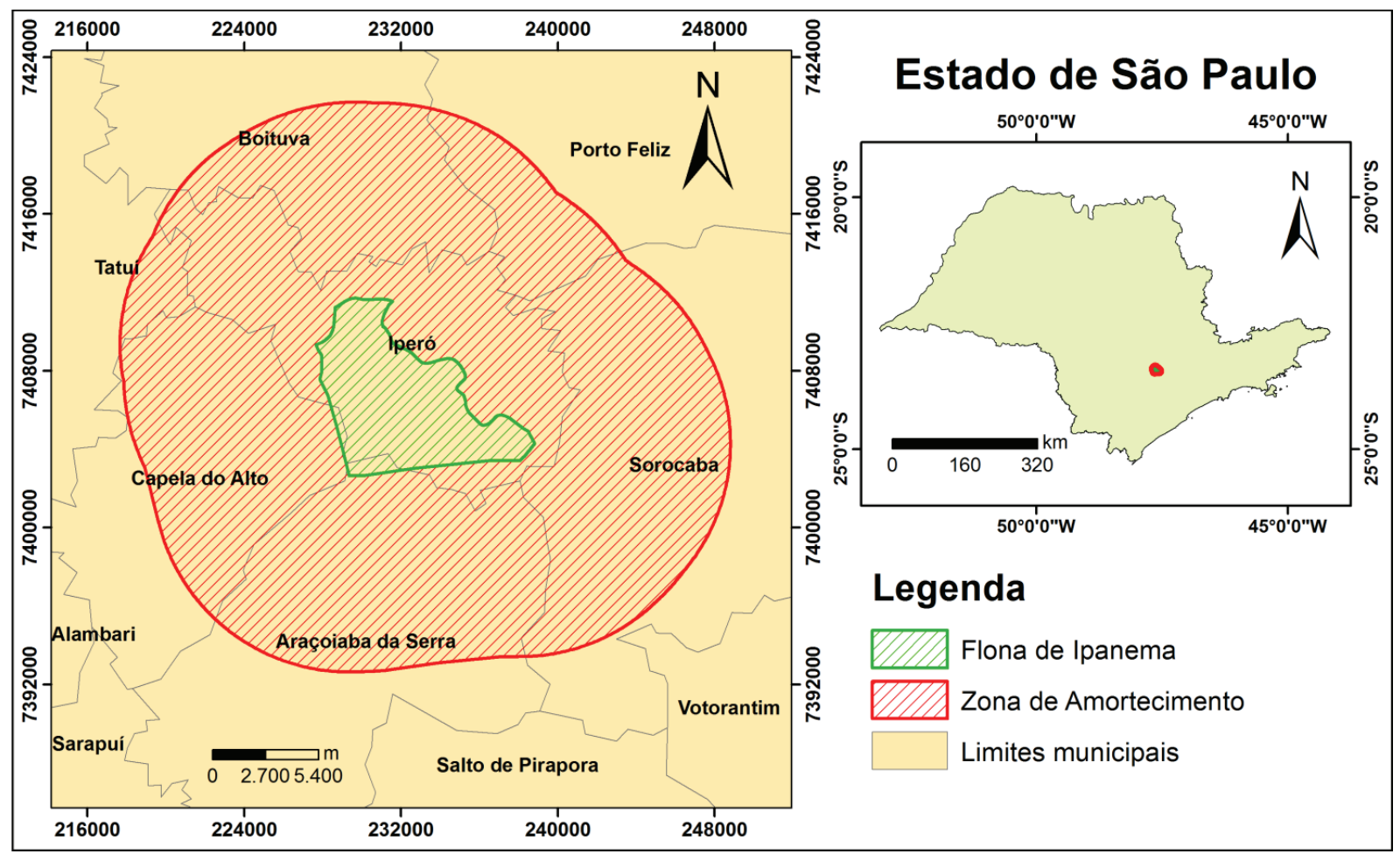

Figura 1 - Localização da área de estudo 
de coordenadas dos eixos x e y através da equação quadrática (), buscando eliminar a distorção entre o Datum das imagens e o das bases do local de estudo. Neste trabalho foi buscado como limite máximo de distorção cartográfica um erro quadrático médio de 0,5 metros (RMS - Root Mean Square).

Em seguida foram realizadas composições coloridas para a classificação do uso do solo e cobertura vegetal. Para a extração das feições relacionadas à cobertura vegetal foi usada a composição falsa-cor com as bandas do infravermelho próximo, infravermelho médio e vermelho, respectivamente no RGB, com a finalidade de diferenciar as áreas de vegetação das demais feições. Outras composições privilegiaram a classificação dos corpos hídricos e das áreas urbanas.

Para a construção do mapa de uso do solo e cobertura vegetal foi empregado o método de classificação supervisionada de Máxima Verossimilhança do software Idrisi Selva. Além disso, foi necessária a digitalização manual de algumas áreas de reflorestamentos e áreas urbanas que não puderam ser classificadas automaticamente, enquanto que a hidrografia, vias e as áreas com presença de cana-de-açúcar foram adicionadas ao mapa de uso do solo e cobertura vegetal a partir de arquivos vetoriais.

A classificação foi realizada como base nas legendas utilizadas pelo IBGE, sendo: Pastagem, Matas, Reflorestamento, Agricultura, Área Urbana, Área de cana-de-açúcar, Hidrografia, Vias e Mata Ciliar (IBGE, 2014). Desta forma, os produtos obtidos resultaram em um mapa de uso do solo e cobertura vegetal da Flona de Ipanema e de sua zona de amortecimento.

Após a classificação foi realizada a interpretação visual das imagens coloridas para inspeção visual dos resultados obtidos com posterior confirmação em campo das classes de uso do solo e cobertura vegetal predominantes e homogêneas com auxílio de um GPS de navegação da marca Garmim modelo Etrex Vista.
Em seguida foi realizada a modelagem da Cadeia de Markov, utilizando o módulo Markov presente no software Idrisi Selva para avaliar as mudanças que se baseiam nas alterações que ocorreram ao longo de uma série histórica através da probabilidade condicional (ESPADA Jr et al., 2014), segundo a equação (1):

(1)

Onde é o estado do sistema no tempo t, é o estado do sistema após o instante e são os estados passíveis de acontecer, que são representados em matrizes de possibilidades de transição. Essas matrizes de transição representam a possibilidade de um determinado estado i permanecer o mesmo ou mudar para o estado j durante um intervalo de tempo (BHARUCHA-REID, 2012; TARUMOTO et al., 2014).

A partir das mudanças e alterações analisadas ao longo da série histórica do ano de 2003 a 2011, foi realizada uma predição para o comportamento do uso do solo e da cobertura vegetal para os próximos 20 anos na área de estudo.

Desta forma, foi possível estimar as futuras alterações das classes de uso do solo e cobertura vegetal da área de estudo e avaliar o avanço da cultura da cana-de-açúcar e de outras atividades antrópicas desenvolvidas na UC e seu entorno.

\section{Resultados e discussão}

Os valores das áreas (ha) obtidas a partir do mapeamento do uso do solo e cobertura vegetal de 2003 a 2011 são mostradas na Tabela 1 .

Analisando a Tabela 1 é possível observar que a classe de uso do solo referente às Matas apresentou os maiores valores de área ao longo do período estudado, tendo sua área máxima alcançada no ano de 2006 (2.822 ha), com exceção para a classe de Matas Ciliares que apresentou decaimento nos valores para o período estudado.

Tabela 1 - Área (ha) das classes de uso do solo na Flona de Ipanema de 2003 a 2011

\begin{tabular}{c|ccccccccc}
\hline $\begin{array}{c}\text { Classes de uso } \\
\text { do solo }\end{array}$ & $\mathbf{2 0 0 3}$ & $\mathbf{2 0 0 4}$ & $\mathbf{2 0 0 5}$ & $\mathbf{2 0 0 6}$ & $\mathbf{2 0 0 7}$ & $\mathbf{2 0 0 8}$ & $\mathbf{2 0 0 9}$ & $\mathbf{2 0 1 0}$ & $\mathbf{2 0 1 1}$ \\
\hline Pastagem & 2.104 & 2.061 & 1.669 & 1.920 & 1.922 & 2.025 & 1.257 & 1.180 & 1.414 \\
\hline Reflorestamento & 47 & 28 & 54 & 49 & 44 & 36 & 52 & 67 & 47 \\
\hline Agricultura & 666 & 635 & 930 & 308 & 404 & 454 & 629 & 1.122 & 1.209 \\
\hline Matas & 2.265 & 2.381 & 2.460 & 2.822 & 2.713 & 2.585 & 3.166 & 2.738 & 2.450 \\
\hline Área urbana & 0,90 & 0,90 & 0,90 & 0,90 & 0,89 & 0,89 & 0,90 & 0,90 & 0,90 \\
\hline Cana-de-açúcar & 5,16 & 5,08 & 5,08 & 5,16 & 5,78 & 12,21 & 12,27 & 12,27 & 12,27 \\
\hline Mata ciliar & 231 & 208 & 200 & 214 & 229 & 206 & 202 & 199 & 186 \\
\hline Área Total & 5.139 & 5.139 & 5.139 & 5.139 & 5.139 & 5.139 & 5.139 & 5.139 & 5.139 \\
\hline
\end{tabular}


As maiores alterações foram observadas para as áreas de Pastagem e Agricultura, sendo que os valores de área para a classe Pastagem chegam a se aproximar de maneira considerável aos de Matas, principalmente no ano de 2003. As áreas de Reflorestamento oscilaram ao longo do período, tendo seu menor valor em 2004 (28 ha) e maior em 2010 (67 ha), enquanto que, a classe de Área Urbana apresentou valores constantes ao longo da série de estudo. É importante destacar que dentro da UC não é permitida a construção de novas edificações. A presença de área urbana no interior da UC com área de 0,9 hectares foi devido à existência de sua sede administrativa e pela presença de assentamentos rurais, segundo consta em seu Plano de Manejo.

Outra importante constatação é o crescente aumento das áreas ocupadas pelas classes de cana-de-açúcar e agricultura a partir de 2007. Nota-se ainda que de 2003 a 2007, o cultivo de cana-de-açúcar ocupava cerca de 5 ha e aumentou para $12 \mathrm{ha} \mathrm{em} \mathrm{2008,} \mathrm{permanecendo} \mathrm{em}$ torno desse valor até 2011 (Tabela 1).

Em relação à área total (5.319 ha) da UC, os maiores percentuais são da classe de Matas que em 2009 atingiu $59,5 \%$ de ocupação da área. A Pastagem é a segunda de maior expressão em termos de área ocupada, correspondendo a 39,6\% em 2003 e 26,6\% em 2011, seguida da Agricultura que variou de $12,5 \%$ (2003) a 22,7\% (2011).

$\mathrm{O}$ fato dos percentuais de Mata Ciliar não se mostrarem significativos, aproximadamente $4 \%$ da área total, deve ser considerado preocupante com relação à gestão ambiental do parque, visto a sua importância para a proteção dos recursos hídricos e demais funções ecológicas.

Na Zona de Amortecimento (ZA) nota-se uma predominância das áreas de Pastagem com relação às demais classes, com destaque para o ano de 2007 que apresentou a maior área (34.643 ha), porém com uma diminuição acentuada a partir do ano de 2008. A classe de Reflo- restamento de um modo geral teve uma diminuição de suas áreas ao longo do período de estudo, bem como as áreas classificadas como Matas.

Dos valores apresentados na Tabela 2, as classes de reflorestamento e agricultura foram as que apresentaram as maiores oscilações nos valores de áreas, sendo que a classe de agricultura atingiu em 2010 sua maior área de ocupação, que corresponde a 33,3\% do total da área estudada, enquanto que a classe de reflorestamento teve sua maior área registrada no início do período estudado.

A classe de área urbana também se mostrou crescente ao longo do tempo, indicando a tendência natural de crescimento das cidades, assim como a classe de canade-açúcar, que também apresentou uma alta taxa de crescimento em 2006 para 2007. Observou-se que grande parte das áreas destinadas a pastagem deram lugar ao cultivo de cana-de-açúcar, que expandiu consideravelmente no entorno da Flona de Ipanema. A prática de cana-de-açúcar cresceu de 3,4\% para aproximadamente 9,2\% dentro da ZA em todo o período estudado.

As regiões que compreendem as classes de Mata Ciliar e Matas, que inclui os biomas de Mata Atlântica, Cerrado e Floresta Estacional Semidecidual, apresentaram uma queda considerável de área se comparados aos valores do ano início e final da análise, que em Matas foi de $63,4 \%$ e, em Mata Ciliar foi de 56,6\% (Tabela 2).

Em termos percentuais referentes à evolução dos tipos de uso do solo na ZA, tem-se a área de pastagem correspondendo a 50,1\% da área total no ano de 2003 com redução para 35,3\% no ano de 2011. A área de agricultura foi a segunda classe com maior expressividade em ocupação de área, de 21,5\% em 2003 a 32,2\% em 2011.

Os mapas de uso do solo e cobertura vegetal da área de estudo considerando tanto a Flona de Ipanema, bem como a Zona de Amortecimento (ZA) são apresentados nas Figuras 2 e 3 para os anos de 2003 e 2011 respectivamente.

Tabela 2 - Área (ha) das classes de uso do solo da ZA no período de 2003 a 2011

\begin{tabular}{c|ccccccccc}
\hline $\begin{array}{c}\text { Classes de uso do } \\
\text { solo }\end{array}$ & $\mathbf{2 0 0 3}$ & $\mathbf{2 0 0 4}$ & $\mathbf{2 0 0 5}$ & $\mathbf{2 0 0 6}$ & $\mathbf{2 0 0 7}$ & $\mathbf{2 0 0 8}$ & $\mathbf{2 0 0 9}$ & $\mathbf{2 0 1 0}$ & $\mathbf{2 0 1 1}$ \\
\hline Pastagem & 30.532 & 34.388 & 33.319 & 33.772 & 34.643 & 31.994 & 28.337 & 20.852 & 21.151 \\
\hline Reflorestamento & 430 & 279 & 311 & 155 & 164 & 172 & 175 & 178 & 172 \\
\hline Agricultura & 13.323 & 10.356 & 12.619 & 9.205 & 5.590 & 8.459 & 12.334 & 19.928 & 19.763 \\
\hline Matas & 5.622 & 4.866 & 3.774 & 4.555 & 5.337 & 4.984 & 4.592 & 4.200 & 3.564 \\
\hline Área urbana & 5.737 & 5.927 & 6.133 & 7.085 & 7.462 & 7.514 & 7.641 & 8.204 & 8.472 \\
\hline Cana-de-açúcar & 2.065 & 2.451 & 2.467 & 3.635 & 4.994 & 5.462 & 5.657 & 5.524 & 5.528 \\
\hline Mata ciliar & 2.170 & 1.612 & 1.256 & 1.472 & 1.689 & 1.294 & 1.143 & 993 & 1.229 \\
\hline Área Total & 59.879 & 59.879 & 59.879 & 59.879 & 59.879 & 59.879 & 59.879 & 59.879 & 59.879 \\
\hline
\end{tabular}




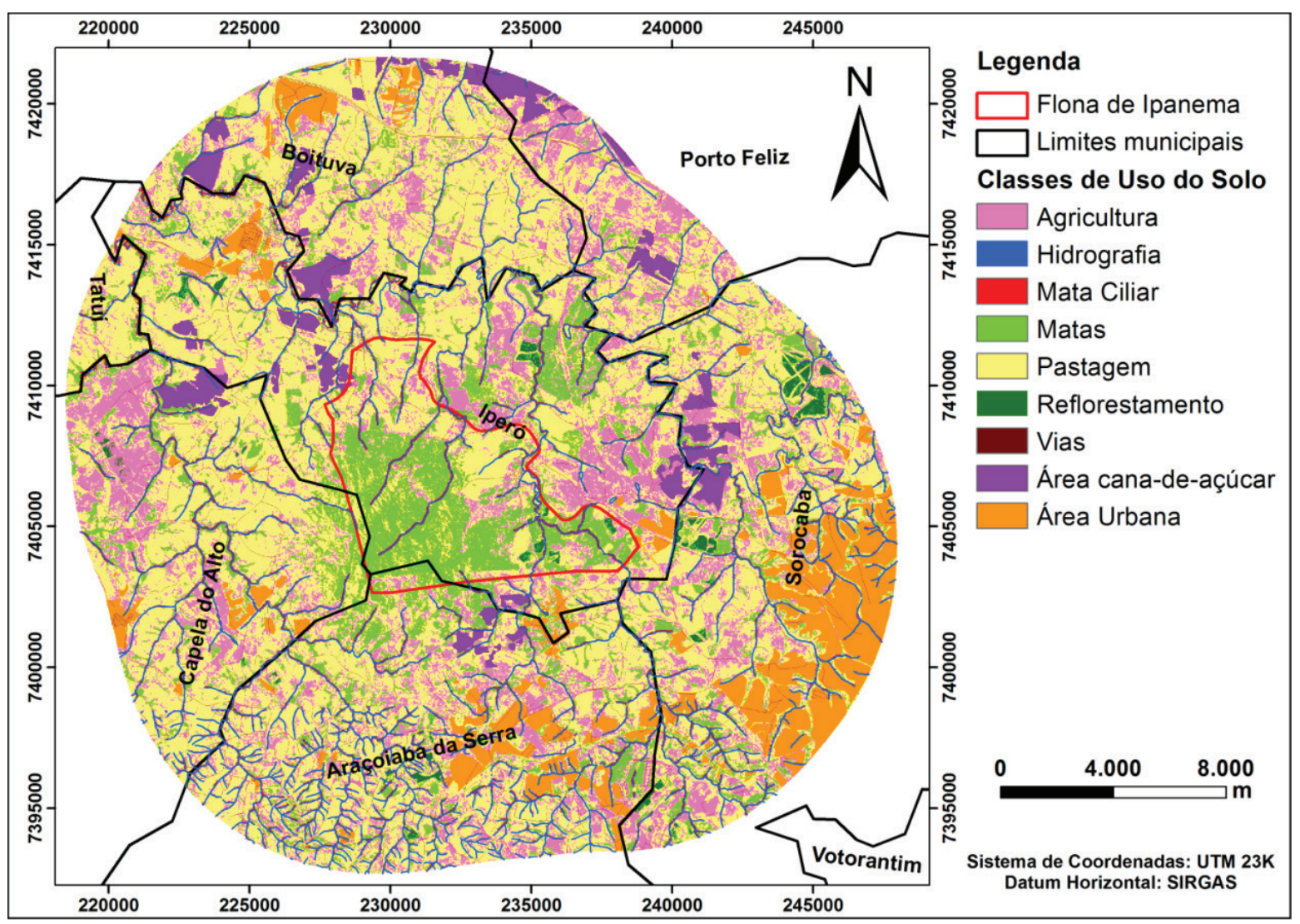

Figura 2 - Uso e ocupação do solo para o ano de 2003

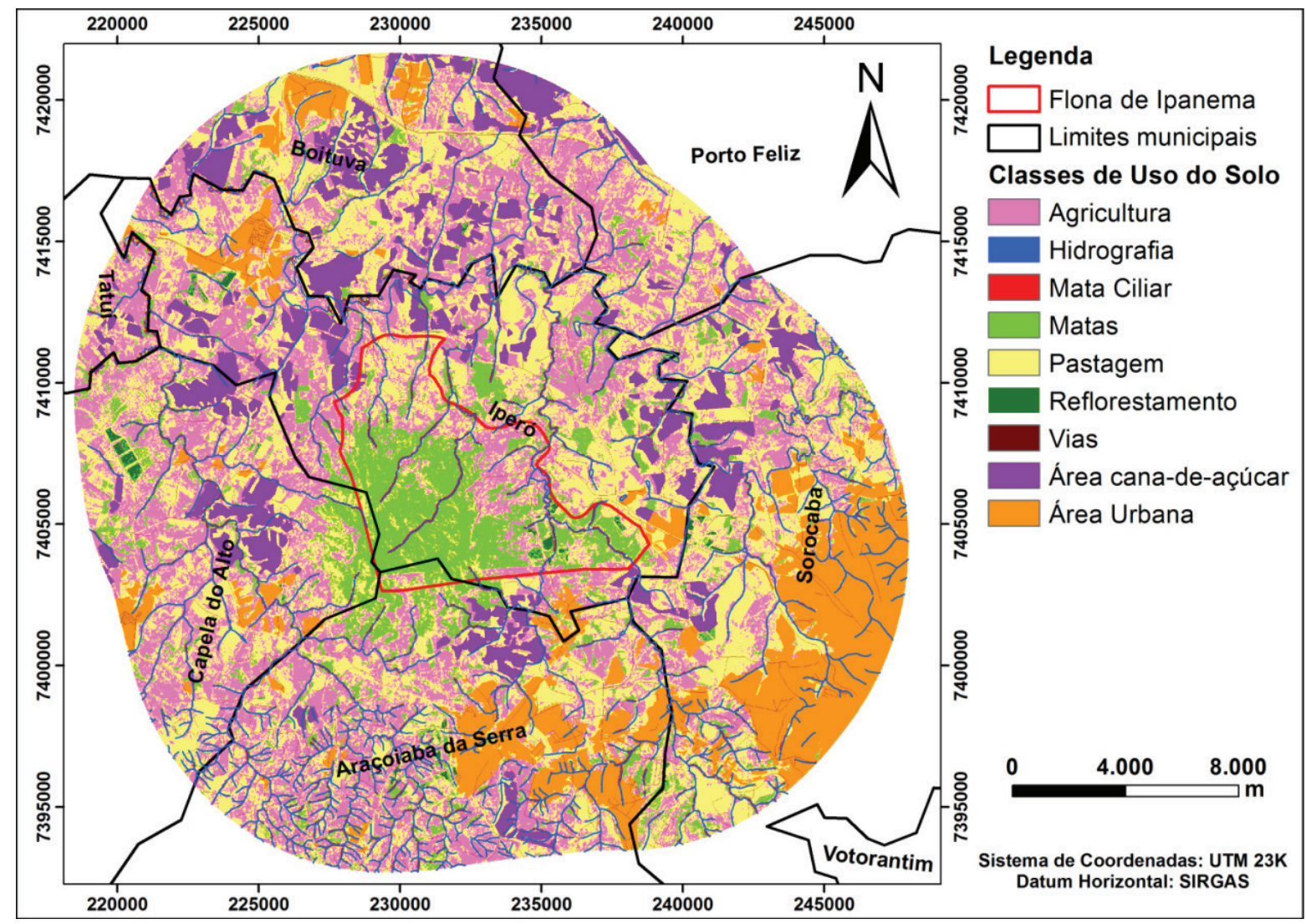

Figura 3 - Uso e ocupação do solo para o ano de 2011 
A classe de Pastagem para a área total do estudo foi a que apresentou os maiores valores de áreas em todos os anos da série de estudo, enquanto que, as classes de Matas, Mata Ciliar e Reflorestamento apresentaram uma queda de área ocupada no período de 2003 a 2011, porém as classes de Agricultura, Cana-de-açúcar e Área Urbana apresentaram um aumento expressivo de área no período de 2003 a 2011 conforme pode ser visto na Tabela 3 .

A agricultura oscilou bastante no período de 2003 a 2009, porém nos dois últimos anos da série apresentou aumentos significativos, ocupando uma área de aproximadamente 21.000 ha. Foi a segunda classe com maior expressividade em ocupação de área, abrangendo 21,5\% da área total em 2003 evoluindo para 32,2\% em 2011.

A cana-de-açúcar, que também é uma atividade agrícola, apresentou uma expansão de suas áreas ao longo do período estabelecido, partindo de 2.070 ha para 5.540 ha, ou seja, dobrando sua expansão (Tabela 3). A prática da cana-de-açúcar cresceu de 3,2\% para aproximadamente $8,5 \%$ dentro da área total de estudo no período de 2003 a 2011.

As regiões que compreendem as classes de Mata Ciliar e Matas da área total de estudo, que pertence aos biomas de Mata Atlântica, Cerrado e Floresta Estacional apresentavam 10.288 hectares em 2003, porém houve um decréscimo para 7.429 ha em 2011, ou seja, juntas perderam 2.859 ha que equivale a $4,4 \%$ da área total.

Em termos percentuais referentes a ocupação e evolução dos tipos de uso do solo e cobertura vegetal, tem-se a área de Pastagem correspondendo a 50,1\% da área total do estudo no ano de 2003 e diminuindo para aproximadamente 34,6\% no ano de 2011.

É possível notar, de acordo com a evolução das classes, um comportamento semelhante entre as classes de

Tabela 3 - Área (ha) das classes de uso do solo da Flona de Ipanema e sua Zona de Amortecimento referente ao período de 2003 a 2011

\begin{tabular}{c|ccccccccc}
\hline $\begin{array}{c}\text { Classes de uso do } \\
\text { solo }\end{array}$ & 2003 & 2004 & 2005 & 2006 & $\mathbf{2 0 0 7}$ & $\mathbf{2 0 0 8}$ & $\mathbf{2 0 0 9}$ & $\mathbf{2 0 1 0}$ & $\mathbf{2 0 1 1}$ \\
\hline Pastagem & 32.636 & 36.449 & 34.988 & 35.692 & 38.565 & 35.019 & 29.594 & 22.032 & 22.565 \\
\hline Reflorestamento & 477 & 307 & 365 & 204 & 208 & 208 & 227 & 245 & 219 \\
\hline Agricultura & 13.989 & 10.991 & 13.549 & 9.513 & 5.494 & 8.913 & 12.963 & 21.050 & 20.972 \\
\hline Matas & 7.887 & 7.247 & 6.234 & 7.377 & 8.050 & 7.569 & 7.758 & 6.938 & 6.014 \\
\hline Área urbana & 5.738 & 5.928 & 6.134 & 7.086 & 5.963 & 6.515 & 7.642 & 8.205 & 8.473 \\
\hline Cana-de-açúcar & 2.070 & 2.456 & 2.472 & 3.640 & 5.000 & 5.474 & 5.669 & 5.536 & 5.540 \\
\hline Mata ciliar & 2.401 & 1.820 & 1.456 & 1.686 & 1.918 & 1.500 & 1.345 & 1.192 & 1.415 \\
\hline Área Total & 65.198 & 65.198 & 65.198 & 65.198 & 65.198 & 65.198 & 65.198 & 65.198 & 65.198 \\
\hline
\end{tabular}

Tabela 4 - Matriz de probabilidades de transição de classes para uma predição dos próximos 20 anos da Flona de Ipanema e sua Zona de Amortecimento

\begin{tabular}{|c|c|c|c|c|c|c|c|c|c|}
\hline & Classe 1 & Classe 2 & Classe 3 & Classe 4 & Classe 5 & Classe 6 & Classe 7 & Classe 8 & Classe 9 \\
\hline Classe 1 & 0,3448 & 0,0025 & 0,3056 & 0,0644 & 0,1271 & 0,1424 & 0,000 & 0,0001 & 0,0132 \\
\hline Classe 2 & 0,3785 & 0,0117 & 0,3296 & 0,0903 & 0,0764 & 0,101 & 0,000 & 0,0000 & 0,0124 \\
\hline Classe 3 & 0,3453 & 0,0026 & 0,3063 & 0,0624 & 0,1365 & 0,1343 & 0,000 & 0,0001 & 0,0127 \\
\hline Classe 4 & 0,3355 & 0,0027 & 0,2963 & 0,1428 & 0,1057 & 0,1084 & 0,000 & 0,0000 & 0,0087 \\
\hline Classe 5 & 0,0012 & 0,0000 & 0,0011 & 0,0000 & 0,9946 & 0,0002 & 0,000 & 0,0000 & 0,0028 \\
\hline Classe 6 & 0,2737 & 0,0012 & 0,2210 & 0,0337 & 0,0352 & 0,4272 & 0,000 & 0,0000 & 0,0081 \\
\hline Classe 7 & 0,0000 & 0,0000 & 0,0000 & 0,0000 & 0,0000 & 0,0000 & 10000 & 0,0000 & 0,0000 \\
\hline Classe 8 & 0,0021 & 0,0000 & 0,0020 & 0,0001 & 0,0004 & 0,0003 & 0,000 & 0,9900 & 0,0051 \\
\hline Classe 9 & 0,3496 & 0,0024 & 0,3147 & 0,0445 & 0,1237 & 0,1038 & 0,000 & 0,0043 & 0,0569 \\
\hline
\end{tabular}


Reflorestamento, Matas e Mata Ciliar, as quais apresentam uma interrupção no decréscimo das áreas por um ano específico, precedido por nova diminuição da área no ano seguinte conforme pode ser visto na Tabela 3.

As classes de Área Urbana e Cana-de-açúcar apresentam uma tendência crescente durante o período analisado para total de estudo, especialmente na zona de amortecimento. Porém as áreas de Pastagem e Agricultura apresentaram valores oscilantes, principalmente a partir dos anos de 2009 e 2010, respectivamente.

Através do procedimento de tabulação cruzada do módulo Markov do Idrisi Selva foram geradas as classes de probabilidade condicional que foram utilizadas na elaboração da matriz de probabilidades de mudança de usos do solo e cobertura vegetal, corrigidas pelo erro proporcional da área de estudo para os próximos 20 anos (Tabela 4), onde as Classes 1, 2, 3, 4, 5, 6, 7, 8 e 9 correspondem respectivamente à Pastagem, Reflorestamento, Agricultura, Matas, Área Urbana, Área de cana-de-açúcar, Hidrografia, Vias e Mata Ciliar.

Segundo o modelo aplicado para a previsão de uma estimativa futura de 20 anos, as classes que apresentaram maior probabilidade de substituírem as classes de Matas e Matas Ciliares serão as Pastagens (33,55\% e $34,96 \%$ respectivamente) e Agricultura (29,63\% e 31,47\% respectivamente). As classes de Reflorestamento, Agricultura, Matas e Área de cana-de-açúcar apresentaram a probabilidade de, respectivamente, 37,85\%, 34,53\%, $33,55 \%$ e $27,37 \%$, de suas áreas serem substituídas por Pastagem. Nota-se que essa tendência de predominância da pastagem já é conferida nos dados obtidos por área, no período de estudo, sendo reforçada por esta tendência. A classe de Agricultura apresentou uma probabilidade de 30,56\%, 32,96\%, 29,63\% e 22,10\% de substituir as classes de Pastagem, Reflorestamento, Matas e Área de cana-de-açúcar, respectivamente. Ressalta-se que o modelo de previsão para a classe de Mata Ciliar apresentou probabilidades críticas de serem substituídas pelas classes de Pastagem, Agricultura, Área Urbana e Área de cana-de-açúcar, com respectivamente, 34,96\%, $31,47 \%, 12,37 \%$ e $10,38 \%$.

A simulação indica que para a predição de 20 anos haverá um aumento da área ocupada por pastagens e agricultura, o que realmente deve acontecer, visto o crescimento populacional no entorno da área de estudo, o que provavelmente deverá demandar maior oferta de alimentos, favorecendo o aumento do desmatamento e a expansão de culturas agrícolas.

A expansão da classe de cana-de-açúcar sobre a área de estudo mostrou que as áreas com maiores probabilidades de serem substituídas é a classe de pastagem e agricultura, porém com probabilidade próxima de pastagem e agricultura aparece a classe de matas, o que é muito preocupante, pois trata-se de uma unidade de conservação que durante o período estudado apresentou uma queda na área ocupada por vegetação na sua ZA e uma oscilação muito grande no seu interior.
Os dados obtidos demonstram a necessidade de atuação mais intensa dos órgãos públicos na gestão da ZA para evitar que a pressão antrópica presente nessa área afete a unidade de conservação, uma vez que, a intensa expansão populacional com pressão imobiliária e agrícola inviabilize a sustentabilidade dessa área de vital importância para a preservação e conservação dos recursos hídricos da região.

\section{Conclusões}

Através da análise do mapeamento temporal do uso do solo e cobertura vegetal da área de estudo foi possível observar a evolução espacial e temporal do uso do solo e da cobertura vegetal. A elaboração dos mapas da área de estudo possibilitaram verificar que, de uma forma geral, Pastagens, Agriculturas com destaque para Canade-açúcar, atuam de maneira incisiva na contribuição das alterações e avanços sobre as classes de Matas e Matas Ciliares tanto no interior da Unidade de Conservação como no seu entorno.

As áreas da classe de pastagem foram as que apresentaram maior predominância na área de estudo. Por outro lado, a presença da cana-de-açúcar, apesar de não ser intensa no interior da UC, mostrou-se com um expressivo avanço em direção aos limites da UC, podendo no futuro ocupar áreas antes dominadas por matas e comprometer a função da manutenção da biodiversidade local.

Por fim, o modelo de previsão das Cadeias de Markov aplicado neste trabalho mostrou-se bastante eficaz quando da análise da evolução espacial e temporal do uso do solo e da cobertura vegetal, bem como da predição dos cenários futuras, o que pode contribuir de maneira significativa com a elaboração ou reformulação de Planos de Manejo, buscando antecipar possíveis desarranjos que possam comprometer a conservação e a preservação ambiental em função dos avanços das atividades antrópicas sobre Unidades de Conservação.

\section{Referências}

ABDALA, K. O.; CASTRO, S. S. Dinâmica de uso do solo da expansão sucroalcooleira na microrregião meia ponte, Estado de Goiás, Brasil. Revista Brasileira de Cartografia, v. 62, n. 04, p. 661- 674, 2010.

ALMEIDA, C. M.; GLERIANI, J. M. Redes Neurais e Autômatos Celulares como uma Plataforma para a Simulação de Mudanças do Uso do Solo Urbano. In: ALMEIDA, Cláudia Ç̂AMARA, G. M.; MONTEIRO, A. M. V. Geoinformação em urbanismo: cidade real x cidade virtual. São José dos Campos, SP: Digital Press, p. 300-323, 2007. 
ALVES, C. D.; FLORENZANO, T. G.; ALVES, D. S.; PEREIRA, M. N. Mapping land use and land cover changes in a region of sugarcane expansion using TM and MODIS data. Revista Brasileira de Cartografia, v. 66, n. 2, p. 337-347, 2014.

ANA, Agência Nacional das Águas. GeoNetwork opensource. Disponível em: <http://metadados.ana. gov.br/geo network>. Acesso em: 20 set. de 2014.

ARIMA, E. Y. et al. Public policies can reduce tropical deforestation: Lessons and challenges from Brazil. Land Use Policy, v. 41, n. 1, p. 465-473, 2014.

BHARUCHA-REID, A. T. Elements of the Theory of Markov Processes and their Applications. Courier Dover Publications, 2012.

CANASAT. Monitoramento da Cana-de-açúcar via imagens de satélite. Disponível em: <http://www.dsr.inpe. br /laf/canasat/index.html>. Acesso em: 20 ago. de 2014.

CHEAVEGATTI-GIANOTTO, A. et al. Sugarcane (Saccharum $X$ officinarum): a reference study for the regulation of genetically modified cultivars in Brazil. Tropical plant biology, v. 4, n. 1, p. 62-89, 2011.

CONAB, Companhia Nacional de Abastecimento. Acompanhamento de safra brasileira: cana-de-açúcar, primeiro levantamento, abril/2012. Conab, Brasília: Conab, 2012.

ESPADA JR, R.; APAN, A.; MCDOUGALL, K. Spatial modelling of natural disaster risk reduction policies with Markov decision processes. Applied Geography, v. 53, n. 1, p.284-298, 2014.

GOLDEMBERG, J.; NIGRO, F. E. Z.; COELHO, S. T. Bioenergia no Estado de São Paulo: Situação atual, Perspectivas, Barreiras e Propostas. Impressa Oficial do Estado de São Paulo: São Paulo, 2008.

GONÇALVES, D. B. Considerações sobre a expansão recente da lavoura canavieira no Brasil. Informações Econômicas, v.39, n.10, p. 70-82, 2009.

IBGE, Instituto Brasileiro de Geografia e Estatística. Manual Técnico de Uso da Terra. Disponível em: <http:// www.ibge .gov.br/home/geociencias/recursosnaturais/ usodaterra/manual_usodaterra.shtm>. Acesso em: 12 out. 2014.

KELLER FILHO, T.; ZULLO JUNIOR, J.; LIMA, P. R. S. R. Análise da transição entre dias secos e chuvosos por meio da cadeia de Markov de terceira ordem. Pesq. Agropec. Bras, v. 9, n. 41, p.1341-1349, 2006.
LINDENMAYER, D. A Checklist for Ecological Management of Landscapes for Conservation. Ecology Letter, v. 11, p. 78-91, 2008.

MARTINELLI, L. A. et al. Agriculture in Brazil: impacts, costs, and opportunities for a sustainable future. Current Opinion In Environmental Sustainability, v. 2, n. 5-6, p.431-438, 2010.

MENEZES, J. P. C.; et al. Correlação entre uso da terra e qualidade da água subterrânea. Eng. Sanit. Ambient. v.19, n.2, p. 173-186, 2014.

MMA, Ministério Do Meio Ambiente. Plano de Manejo da Floresta Nacional de Ipanema. IBAMA, 2005.

MULLER, M. R.; MIDDLETON, J. A Markov model of land-use change dynamics in the Niagara Region, Ontario, Canada. Landscape Ecology, v. 9, n. 2, p. 151-157, 1994.

NEVES, M. F.; CONEJERO, M. A. Sistema agroindustrial da cana: cenários e agenda estratégica. Econ. Apl., v. 11, n. 4, p. 587-604, 2007.

OKA-FIORI, C.; FIORI, A. P.; HASUI, Y. Dinâmica da ocupação do solo da bacia do Rio Itiquira, Revista RA'E GA, Curitiba, n. 7, p. 19-31, 2003.

PEIXE, A. S. M.; TORRES, M. F. A. Degradação Ambiental em Fragmento de Mata Atlântica: Reserva Ecológica do Jardim Botânico do Recife-PE. Revista Brasileira de Geografia Física, Pernambuco, v. 1, n. 04, p.762-778, 2011.

PEREIRA, J. R. et al. Gestão social dos territórios da cidadania: o zoneamento ecológico-econômico como instrumento de gestão do território noroeste de Minas Gerais. Cadernos EBAPE. BR, v. 9, n. 3, p. 724-747, 2011.

PEREIRA, P. S. et al. Avaliação da integridade ecológica de rios em áreas do zoneamento ecológico econômico do complexo hidrográfico Guapiaçu-Macacu, RJ, Brasil. Ambiente \& Água-An Interdisciplinary Journal of Applied Science, v. 7, n. 1, p. 157-168, 2012.

RIBEIRO, E. F. et al. Efeito de Atividades Antrópicas Sobre a Mata do Instituto Federal de Educação Ciência e Tecnologia Minas Gerais - campus São João Evangelista (IFMG-SJE). Revista Agroambiental, v.3, n.2. p. 83-92, 2011.

RODRIGUES, J. E. R. Sistema Nacional de Unidades de Conservação. São Paulo, 2005.

SANG, L.; ZHANG, C.; YANG, J.; ZHU, D.; YUN, W. Simulation of land use spatial pattern of towns and villages based on CA-Markov model. Mathematical and Computer Modelling, v. 54, n. 3, p. 938-943, 2011. 
SOFFIANIAN, A.; MADANI, E. S.; ARABI, M. Risk assessment of heavy metal soil pollution through principal components analysis and false color composition in Hamadan Province, Iran. Environmental Systems Research, v. 3, n. 1, p. 1-14, 2014.

SOMMER, J. A. P.; SALDANHA, D. L. Análise Temporal do Uso e Cobertura dos Solos no Município de São José dos Ausentes, Rio Grande do Sul, Brasil. Revista Brasileira de Geografia Física, v. 1, n. 1, p.12-18, 2012.

SOUZA, P. C.; MARTOS H. L. Estudo do uso público e análise ambiental das trilhas em uma unidade de conservação de uso sustentável: Floresta Nacional de Ipanema, Iperó-SP. Revista Árvore, v.1, n.32, p. 91-100, 2008.

TARUMOTO, M.; PINHEIRO, M.; RODRIGUES, E. Estudo de funções de verossimilhança para modelagem de processos de Markov aplicados ao estudo da concentração de poluição. Revista da Estatística da Universidade Federal de Ouro Preto, v. 3, n. 3, p. 481-485, 2014.

VARAJÃO, C. A. C. et al. Estudo da Evolução da Paisagem do Quadrilátero Ferrífero (Minas Gerais, Brasil) por meio da Mensuração das Taxas de Erosão e da Pedogênese. R. Bras. Ci. Solo, v.1, n.33, p. 1409-1425, 2009.

WANG, S. Q.; ZHENG, X. Q.; ZANG, X. B. Accuracy assessments of land use change simulation based on Markov-cellular automata model. Procedia Environmental Sciences, v. 13, p. 1238-1245, 2012. 